\title{
Dando vida ao reconhecimento territorial ${ }^{4}$
}

\author{
Breathing life into the territorial acknowledgement
}

\section{Dando vida al reconocimiento territorial}

\author{
Melanie Janzen ${ }^{2}$ \\ University of Manitoba, Departamento de Currículo, Ensino e Aprendizagem, Professora \\ associada. \\ https://orcid.org/0000-0003-2881-3436
}

\begin{abstract}
Todos nós somos produtos severamente danificados: por um lado, os canadenses são prejudicados por sua história de pilhagem, pela constante racionalização da sua gigante preponderância sobre espaço, e seu controle do tempo; por outro lado, os povos indígenas são prejudicados por sua falta de direitos, tão prejudicados que resolver isso será um pesadelo. Mas devemos fazê-lo. (MARACLE, 2015, p. 126).
\end{abstract}

Resumo: A problemática da colonização no Canadá e da relação com os povos indígenas é central. Os campi da Universidade de Manitoba, no Canadá, estão localizados nas terras originais de Anishinaabeg, Cree, Oji-Cree, Dakota, povos Dene e no território da Nação Métis. Diante desse fato, a autora se reflete sobre a indação: Como, eu como colona, pesquisadora e professora, ofereço um reconhecimento territorial significativo quando estou tão claramente situada em - e me benefício de - terras roubadas? Desse modo, a autora revisita o significado do reconhecimento territorial (de viver nas terras originárias dos povos indígenas) no ensino, sondando autobiograficamente sentidos que podem dar vida a atos de reconhecimento.

Palavras-chave: Povos indígenas. Ensino. Reconhecimento territorial.

Abstract: The problem of colonization in Canada and the relationship with indigenous peoples is central. The campuses at the University of Manitoba, Canada, are located in the original lands of Anishinaabeg, Cree, Oji-Cree, Dakota, Dene peoples and in the territory of the Métis Nation. In view of this fact, the author reflects on the induction: How, as a colonist, researcher and teacher, do I offer significant territorial recognition when I am so clearly situated in - and benefit from - stolen land? In this way,

\footnotetext{
Traduzido por Paula Lemos, Mestra em Educação UFRJ, bolsista Proatec Uerj, a partir do original: JANZEN, Melanie. Breathing life into the territorial acknowledgment. Transnational Curriculum Inquiry, Rio de Janeiro, v. 16, n. 2, p. 74-81, 2019. Revisto por Clarissa Craveiro, professora da Universidade Federal Fluminense (UFF/EAR) e líder do Grupo de Pesquisas Curriculares (GPeC). E-mail: clarissacraveiro@id.uff.br. A publicação da tradução foi autorizada pela Transnational Curriculum Inquiry.

2 Doutora pela University of British Columbia, Canadá; Mestre pela University of Manitoba, Canadá.
} 
the author re-visits the significance of territorial acknowledgment lof living on the original lands of Indigenous peoples) in teaching, probing autobiographically the meanings that can breathe life to acts of acknowledging.

Keywords: Indigenous peoples. Teaching. Territorial acknowledgment.

Resumen: El problema de la colonización en Canadá y la relación con los pueblos indígenas es central. Los campi de la Universidad de Manitoba, Canadá, están ubicados en las tierras originales de los pueblos Anishinaabeg, Cree, Oji-Cree, Dakota, Dene y en el territorio de la Nación Métis. Ante este hecho, el autor reflexiona sobre la cuestión: ¿Cómo, como colona, investigadora y docente, ofrezco un reconocimiento territorial significativo cuando estoy tan claramente situado en - y me beneficio - de tierras robadas? De esta forma, el autor revisa el significado del reconocimiento territorial (de vivir en las tierras originarias de los pueblos indígenas) en la docencia, indagando autobiográficamente los significados que pueden dar vida a los actos de reconocimiento.

Palabras clave: Pueblos indígenas. Enseñando. Reconocimiento territorial.

Recebido em 25 de novembro de 2020

Aceito em 4 de janeiro de 2021

\section{INTRODUÇÃO}

Era uma daquelas encantadoras manhãs, o céu de um azul cerúleo iluminado das pradarias, o fundo de lama do Rio Vermelho silenciosamente deslizando sem ondulações, e o ar já quente, claro e cheio de promessas de um dia quente de verão. Estava cruzando a trilha do rio com a minha bicicleta, em direção ao Museu Canadense de Direitos Humanos (CMHR), onde estava dando aula com outro professor em um curso de verão. Enquanto seguia a trilha ao longo da margem, o caminho virou suavemente para a esquerda e entrou em uma clareira na qual minha visão foi capturada pelo imenso edifício do museu à distância. $A$ torre de vidro da esperança, saindo do museu e perfurando o céu nublado, era iluminada pelo sol, enquanto a margem gramada do rio estava diante de mim aos meus pés. Parei para tirar uma foto, pensando que poderia adicioná-la aos meus slides antes da aula começar.

Trabalho em um campus universitário rodeado nos três lados pelo sinuoso Rio Vermelho. 0 campus é situado no território do Tratado $\mathrm{Um}^{3}$ terras originais de Anishinabe, Cree, Oji-Cree, Dakota, povos Dene, e no território da Nação Métis. De acordo com Aimée Craft (2013), advogada e estudiosa indígena (Anishinaabe-Métis), o Tratado Um é significativo na história

3 Tratado Um é o nome dado a um acordo estabelecido em 3 de agosto de 1871 entre a Coroa Imperial da Grã-Bretanha e Irlanda e as nações Anishinabe e SwampyCree, no atual Canadá. 
das relações entre o governo canadense e os povos indígenas, pois foi o primeiro dos tratados numerados e foi "a articulação na qual a expansão agrícola ocidental e a ferrovia nacional estavam repousando." (CRAFT, 2013, p. 39). Historicamente significativo, dada a história colonial compartilhada deste lugar, o Tratado Um permanece importante, pois os canadenses trabalham para entender a história colonial deste país, bem como as estruturas coloniais atuais e suas implicações.

Nosso campus, assim como outras instituições em todo o Canadá, tem desenvolvido um reconhecimento territorial que pretende respeitara terra e seus povos originais, os tratados, os efeitos prejudiciais da colonização e nossa responsabilidade coletiva em uma era de verdade e reconciliação. Entretanto, isso não ocorre sem problemas. Como, eu como colona, pesquisadora e professora, ofereço um reconhecimento territorial significativo quando estou tão claramente situada em - e me benefício de - terras roubadas?

\section{RECONHECIMENTO TERRITORIAL TRADICIONAL}

Os campi da Universidade de Manitoba estão localizados nas terras originais de Anishinaabeg, Cree, Oji-Cree, Dakota, povos Dene e no território da Nação Métis. Nós respeitamos os tratados que foram feitos nesses territórios e reconhecemos os danos e erros do passado e nos dedicamos a avançar em parcerias com as comunidades indígenas, num espírito de reconciliação e colaboração (UNIVERSITY OF MANITOBA, 2019).

Muitos colegas mais velhos e indígenas aconselham que, a fim de tornar um reconhecimento territorial significativo, aquele que fornece o reconhecimento deve criar um vínculo pessoal com o reconhecimento. Em outras palavras, aquele que confere o reconhecimento deve considerar o que o reconhecimento significa para eles e elas pessoalmente. Como uma colona branca que cresceu perto do rio Vermelho nesta cidade, sinto como se tivesse conexões históricas, geográficas e sociais com este lugar. A foto que tirei naquela manhã parecia uma imagem agradável refletindo o rio, a cidade e minhas conexões pessoais desenvolvidas aqui. No entanto, quando olhei para a foto novamente, fiquei surpresa ao ver como a câmera havia capturado algumas das camadas complexas do passado e do presente colonial da cidade. A foto me forneceu um texto que era mais rico do que eu imaginara, mas, como explorarei, só poderia me levar até aqui. 
Fotografia 1 - Fotografia para reconhecimento territorial

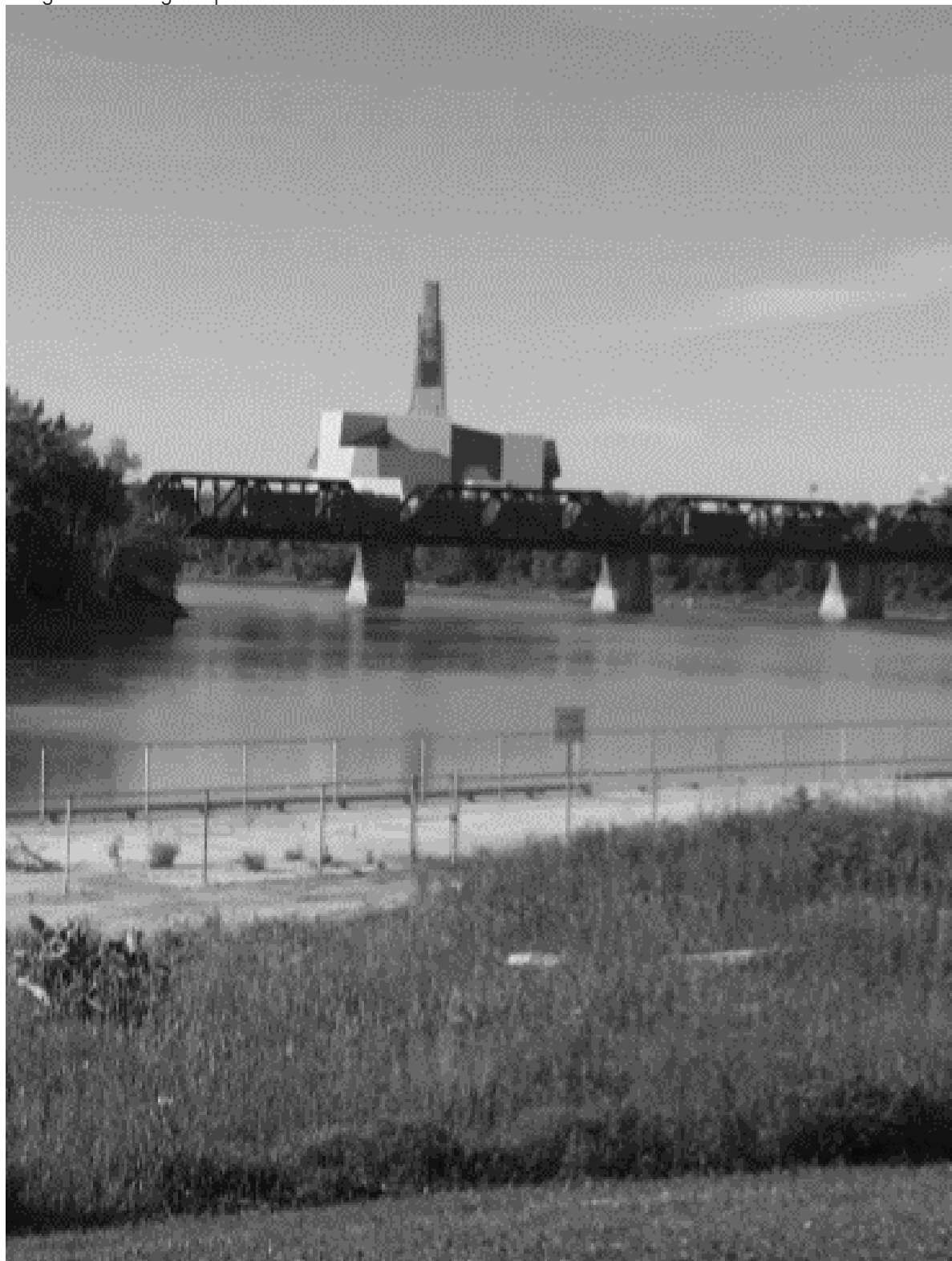

Fonte: $\mathrm{o}$ autor. 


\section{MEU (INSUFICIENTE E INCOMPLETO) RECONHECIMENTO TERRITORIAL}

Gostaria de reconhecer que estamos no território do Tratado Um, lar dos Cree, 0jiCree, Dakota e povos Dene e território da Nação Métis. Uso a fotografia que você viu projetada aqui para representar visualmente nossa história colonial e as complexidades das relações daqueles que aqui residem. Gosto de usar essa fotografia para lembrar a mim mesma do meu lugar no território do Tratado Um e o trabalho que é exigido de mim como uma colonizadora deste lugar.

Você pode ver como, nesta foto bidimensional, a imagem aparece em camadas nas estrias horizontais. Na segunda camada de baixo, vemos o rio lamacento (para o qual a palavra Cree é "Winnipeg”; "Win" significa lamacento e "Nippee”, água). 0 rio corta a região, seguindo a partir do The Forks onde os povos indígenas têm se reunido há milênios. 0 rio representa os sistemas robustos de comércio e viagens dos Primeiros Povos e o vigoroso comércio de peles facilitado, em parte, pelo The Voyageur. Na camada diretamente acima do rio, vemos a ponte enferrujada da linha férrea como uma navalha cortando a imagem a terra deste país, e representando a chegada, a expansão e a colonização física desse local. $\mathrm{Na}$ camada logo acima e dominando o olhar, vemos o Museu Canadense dos Direitos Humanos e sua agora famosa imagem da torre de vidro da esperança jorrando sua imensa base de pedra tyndal. 0 museu foi e é um projeto controverso, construido nas margens do The Forks (um local indígena sagrado) e diretamente no topo da maior descoberta arqueológica de artefatos indígenas do Canadá. Com o objetivo de ser um farol para nossa cidade e nação, o museu simultaneamente atua como um para-raios à controvérsia e à crítica ponderada. Finalmente, em primeiro plano (na parte inferior da foto) e facilmente esquecido, vemos uma margem indefinida do rio, gramada e plana, com a decrépita doca de Alexander na beira.

Em Winnipeg, basta dizer que este é a doca de Alexander - todos aqui conhecem a história recente e o horror desse local. No entanto, se eu estivesse dando boas-vindas a pessoas que não conhecem o significado dessas docas, também deveria lembrá-las de que: A doca Alexander é um marco significativo em nossa cidade, pois é o local onde o corpo de Tina Fontaine, de 15 anos, embrulhado em um saco de lixo, foi retirado do rio. Encontrar seu pequeno corpo provocou indignação em nossa cidade e se espalhou por todo o país, finalmente provocando o início da Investigação de Mulheres e Meninas Desaparecidas e Assassinadas...

Mas não costumo dizer isso - as pessoas que vivem aqui sabem disso.

Descrever a foto como parte do meu reconhecimento territorial pareceu mais significativo e fiquei satisfeita com isso - por um tempo. Na criação desse reconhecimento territorial, usando a imagem e suas camadas de texto histórico e visual juntamente com o comentário, pensei que 
isso era uma tentativa de "dar vida ao que são essencialmente documentos de relacionamento." (CRAFT, 2013, p. 12). Craft (2013, p. 16) explica que os tratados foram acordos maiores do que o real documento do tratado e que eles tinham como premissa as relações: "Relações com e entre nós, relações com outros seres animados." A imagem forneceu contexto e uma conexão pessoal com o local, mas... quem estava em relação aqui? E com quem?

\section{RECONHECIMENTO TERRITORIAL: “PALAURAS BONITAS, MAS UAZIAS"}

Recentemente (e talvez por muito mais tempo), povos indígenas, acadêmicos e líderes comunitários têm questionado o valor da terra e dos reconhecimentos territoriais. Por exemplo, Audrey Siegl, do Musqueam, afirmou que os reconhecimentos territoriais são "apenas tokenismo, palavras bonitas, mas vazias, ditas para que possamos ser pacificados por pelo menos um pouco mais." (HERGESHEIMER, 2016). Da mesma forma, a professora indígena Laara Fitznor, que geralmente apoia a intenção de reconhecimento de terras, alerta que precisamos lembrar que esses reconhecimentos são "apenas palavras" (BRASS, 2018). Isso me fez pensar, quais e de quem são as narrativas que estão sendo mantidas nesses reconhecimentos?

Lembro-me da metáfora do forte de Dwayne Donald (2012) e como isso se tornou um símbolo que reificava a divisão entre povos indígenas e colonizadores. Penso que poderia ser argumentado que os reconhecimentos territoriais agem de maneiras similares; como exemplos de uma lógica de fronteira colonial (DONALD, 2012) que trabalha para manter as divisões entre colonos e povos indígenas. Em outras palavras, eles estão se tornando outro exemplo de prática institucionalizada que assume e mantém a "suposição de que as experiências e perspectivas dos povos aborígines no Canadá são suas próprias preocupações culturais separadas." (DONALD, 2012, p. 92). Como Laara Fitznor aponta, embora ela aprecie que a universidade tenha um reconhecimento de terras, isso não reflete sua perspectiva como pessoa Cree e membro do corpo docente indígena. Fitznor disse: "Quando eu li, eu disse 'Esta não sou eu', porque eles estão dizendo 'desculpe' a você e eu estou lendo - eu digo 'desculpe' a mim mesma?" (BRASS, 2018). Parece que o reconhecimento reitera a lógica colonial, reforçando o domínio colonial como "uma espécie de vala cultural - separando aborígines dos canadenses." (DONALD, 2012, p. 93). É possível que os reconhecimentos do tratado sejam mais do que apenas palavras vazias, movimentos da lógica coloniale Donald (2012, p. 93) sugere que é preciso "contestar a lógica da fronteira colonial, enfatizando a relacionalidade e a conectividade que advêm da convivência em um determinado local por um longo tempo." 


\section{DE UOLTA AO COMEÇO}

Às vezes para seguir em frente, precisamos ir ao começo. (MARACLE, 2015, p. 120).

Após a assinatura do Tratado Um, em 1871, o governo canadense começou a facilitar a colonização das pradarias, oferecendo grandes parcelas de terra aos europeus. No final de 1800 , os Menonitas do sul da Rússia chegaram à província "recém-criada" de Manitoba. Meus bisavôs - maternos e fraternos - chegaram ao Canadá como imigrantes que buscavam refúgio da perseguição por serem objetores de consciência ${ }^{4}$ devido a suas crenças religiosas. De acordo com documentos do governo de Manitoba, o governo procurou "atrair" esses "agricultores diligentes" para as pradarias, concedendo-lhes isenções do serviço militar, liberdade religiosa e terras para colonização (LEDOHOWSKI, 2003). Assim, os Menonitas receberam reservas ou "grandes extensões de terra para seu assentamento exclusivo" e, posteriormente, desenvolveram a "Reserva Leste" (1874) e a "Reserva Oeste" (1875) nos respectivos lados do Rio Vermelho (KLASSEN, 2018). Usando discursos coloniais de terra nullius e reforçada por narrativas da construção do Canadá, a terra foi considerada desabitada e livre para ser tomada. Essa "lógica da eliminação" (TUCK; GAZTAMBIDE-FERNANDEZ, 2013, p. 73) é um evento do colonialismo "no qual o colonizador vem para ficar, tornando-se soberano e árbitro da cidadania, civilidade e conhecimento." As terras de reserva concedidas aos Menonitas permitiram o estabelecimento de 87 aldeias e terras agrícolas associadas, pelas quais eles não pagavam nada, e que agora são algumas das terras agrícolas mais produtivas e lucrativas das pradarias.

Não é por acaso que as promessas do governo de terras para imigrantes europeus coincidiram com o desenvolvimento de Escolas Residenciais, que ativamente removeram crianças de suas casas e terras, e coincidiram com a Lei Indiana (1876), que foi posta em prática controlar os povos indígenas e seus movimentos. De um modo geral, os canadenses estão começando a entender que essas histórias coloniais de descoberta e criação da nação eram narrativas estabelecidas e perpetuadas pelo Estado colonizador, em um esforço para controlar e colonizar a terra e seus primeiros povos. No entanto, essas não foram as histórias que nos contaram quando crescemos, nem nós - pelo menos na história da nossa família - articulamos essas questões em relação à nossa implicação pessoal. As histórias que nos foram contadas reforçaram narrativas heroicas de colonos do Canadá. Por exemplo, como objetores de consciência, os Menonitas foram forçados a fugir de sua terra natal por medo de perseguição e, ao chegarem ao Canadá, construíram uma

\footnotetext{
Objetores de consciência são os que se negam a participar do alistamento militar. Nota da revisora da tradução.
} 
vida através de seu trabalho duro e inovações na agricultura. As casas de relva, estruturas temporárias construídas antes que os materiais fossem seguros para moradias mais permanentes, constituem uma metáfora interessante para os colonos das pradarias, para a diligência, perseverança em condições extremamente dificeis, mas também para ilustrar o quão imersos na terra estavam esses imigrantes - literalmente se enterrando na paisagem para sobreviver ao inverno. Essas narrativas foram reforçadas em histórias de família, no currículo escolar e em ideologias multiculturais que pintaram o Canadá como uma grande fronteira, corajosamente estabelecida e aprimorada através da diligência e do trabalho duro. Exaltando os valores Menonitas do pacifismo e os contos heroicos da imigração, a história de nossa família foi legitimada como uma "história da criação" usada para "ocultar a teleologia da violência e da dominação que caracterizam a colonização." (TUCK; GAZTAMBIDE-FERNANDEZ, 2013, p. 74).

Na história da criação Menonita de retidão e luta corajosa, as histórias dos Primeiros Povos desta terra estavam ausentes. Não me lembro de uma única história de família que envolvesse as relações da minha família com os povos indígenas. Era como se essas pessoas - cuja terra ocupamos - simplesmente não existissem. É essa lógica de eliminação que busca não apenas dominar um grupo de pessoas, mas é principalmente motivada pela aquisição de terras (TUCK; GAZTAMBIDE-FERNANDEZ, 2013). É importante ressaltar que, nesse movimento histórico e contemporâneo, no qual a "violência de invasão não está contida no primeiro contato ou nas infelizes dores de parto de uma nova nação, mas é reafirmada a cada dia de ocupação" (TUCK; GAZTAMBIDE-FERNANDEZ, 2013, p. 73), os Menonitas ainda estão lá e fazendas têm sido passadas por gerações.

Ao buscar informações sobre o que foi eliminado na história de criação de nossa família, encontrei uma notícia, publicada on-line pela CBC, sobre a exploração de povos indígenas que foram recrutados por agricultores Menonitas para colher beterrabas nas décadas de 1940 a 1980 (CARREIR0, 2017). Os agricultores alistariam indígenas das reservas, com salários e acomodações promissores. Como foi relatado, ao invés disso os trabalhadores receberam um trabalho árduo, salário mínimo, sem comida ou mesmo água. Quando compartilhei essa história com minha mãe, nascida e criada nas terras da reserva Menonita, ela pensou em voz alta: "Me pergunto que outros pequenos segredos existem." Ela continuou a me contar as lembranças de sua avó dando pão aos "índios" que apareciam na porta implorando por comida. Teria sido importante para os Menonitas defender as narrativas salvadoras, reificadas pela construção dos povos indígenas como "menos do que os outros ou nãocivilizados" e, ao fazê-lo, permitiram que os colonizadores sentissem - e reafirmassem - o domínio "ajudando" os "pobres". Tais histórias de criação "cobrem os trilhos" do colonizador, mascarando a violência da dominação e o apagamento (TUCK; GAZTAMBIDE-FERNANDEZ, 2013). 
Minha mãe foi sábia em relação a essas e outras hipocrisias que surgiram ao longo de sua educação, deixando sua comunidade no dia em que completou seu exame final do ensino médio. Ela não conseguia conciliar os ensinamentos da fé com as maneiras pelas quais via a vida sendo vivida pelas pessoas ao seu redor. Por exemplo, o pai dela, que havia se alistado na Segunda Guerra Mundial como um meio de sustentar sua familia, foi constantemente rejeitado pela comunidade ao retornar, teve emprego e acesso à igreja recusados por causa de sua violação das crenças pacifistas da religião. Arriscar a vida para colocar comida na mesa não era um delito perdoável.

Donald (2012, p. 93) explica que "imaginar a descolonização das relações aboríginescanadenses começa com o rastreamento cuidadoso da natureza colonial dessas relações no passado e hoje - e o reconhecimento que a lógica da fronteira colonial continua a ter uma enorme influência sobre como a relação é conceitualizada." Desenterrar histórias que revelam as relações entre os colonos Menonitas e os povos indigenas ajuda a revelar estruturas de poder subjacentes, iniquidades, racismo e falhas na relacionalidade ética. Ainda assim, essas histórias são escassas. A pergunta de minha mãe - "Gostaria de saber que outros pequenos segredos existem" - indica os esforços feitos pelas comunidades de colonos para ocultar suas verdades inconvenientes e antiéticas e as narrativas dominantes em jogo, escondendo esses segredos. No entanto, é através de esforços contínuos para revelar os segredos sujos que uma "condição compartihada em que colonizadores e colonizados se conhecem" (DONALD, 2012, p. 93) pode ser promovida.

Meus bisavós e avós eram muito pobres. Eles nunca possuiram terras agrícolas, no entanto se beneficiaram do trabalho permitido pelos assentamentos nas terras. No fim das contas, meus pais se mudaram de suas comunidades Menonitas no Sul de Manitoba para Winnipeg, procurando trabalho e, talvez, também liberdade das comunidades religiosas que eles frequentemente achavam opressivas. Depois de se casarem e alugarem uma propriedade no extremo norte da cidade, meus pais compraram uma pequena casa perto do rio Vermelho, no território do Tratado Um - embora não soubessem disso. 0s tratados não eram reconhecidos nos anos 1970. A hipoteca era um imenso fardo financeiro. No entanto, meus pais conseguiram criar uma vida de classe trabalhadora para nossa familia, devido a sua dedicação e ao trabalho duro, bem como ao seu privilégio branco. Embora meu pai tivesse abandonado a escola no primeiro ano do ensino médio para trabalhar, ele foi treinado e empregado em um comércio sindicalizado. Como família, nos beneficiamos muito de seu trabalho, que proporcionava bons salários e benefícios. Isso possibilitou que eu e minha irmã pudéssemos ir à Universidade - entre nossas dúzias de primos, fomos as primeiras capazes de realizar isso.

Como a maioria das crianças canadenses coloniais da época, minha irmã e eu fomos educadas em narrativas cor de rosa da história do Canadá, refletindo ideais do 
multiculturalismo. Os "nativos" foram retratados em nossos livros como figuras históricas que se beneficiaram da colonização. Reconhecemos essa história criando iglus de cubos de açúcar e lendo um poema de Pauline Johnson, ignorando completamente os povos das Primeiras Nações e Métis do passado e do presente em cujas terras essa educação estava ocorrendo. Exceto pela história de Louis Riel, que naquela época ainda era considerado um traidor e merecia o castigo de ser enforcado. Esses pequenos eventos curriculares (na medida em que ocupam pouco tempo ou espaço) são ilustrações gritantes das maneiras pelas quais o currículo era - e ainda é - uma estrutura hegemônica. Nosso currículo refletia (e ainda reflete) versões "idealizadas e mitologizadas" (DONALD, 2012, p. 95) da história, que "se transformam em expressões hegemônicas de estruturas de valores existentes e visões de mundo do grupo dominante na sociedade." (DONALD, 2012, p. 95). 0 currículo circulava histórias de corajosos colonos de Manitoba - dos Menonitas aos islandeses -, todos pioneiros da fronteira e criadores desta nação, apagando qualquer existência e influência reais dos povos indígenas no passado e ignorando sua existência no presente.

\section{REDUZINDO O FOGO}

[...] o fogo é reduzido, até a próxima vez que nos encontrarmos. Nós não terminamos nosso trabalho. Nosso trabalho nunca termina. As coisas mudam, nós mudamos. Vamos discutir isso novamente. EÉlder Elmer Courchene, em CRAFT, 2013, p. 113).

Tentei considerar a presença e a cumplicidade da minha família no passado colonial deste país, procurando reconsiderar os mitos Menonitas de vitimização e heró́smo e narrativas de colonização e sobrevivência, a fim de reconhecer as múltiplas verdades que existem em nossa criação - e mais importante, as histórias que estavam ausentes. lsso ajuda a iluminar os presentes que recebemos e a dívida que devemos. Este é um exercício que "busca entender mais profundamente como nossas diferentes histórias e experiências nos posicionam em relação um ao outro", desenterrando nossa "relacionalidade e conectividade que vende viver em um determinado lugar por um longo tempo." (DONALD, 2012, p. 103). № entanto, este exercício está inacabado e permanece inadequado.

Certamente, essa reflexão corre o risco de sofrer críticas sobre olhar para o próprio umbigo, à recirculação da narrativa dos colonos e à recentralização da brancura e do meu próprio privilégio. E assim, como Lee Maracle (2015, p. 126) nos lembra na citação de abertura deste artigo, classificar isso corre o risco de ser um pesadelo, "mas o faça, precisamos." Na melhor das hipóteses, esse esforço pode ser visto como uma tentativa de desvendar os segredos sujos de nosso passado, a fim de informar uma história da 
criação mais verdadeira. Espero que isso possa ser visto como uma provocação de uma conversa sobre nosso passado colonial compartilhado e como ele opera no presente; uma consideração do que um reconhecimento territorial pode significar - para mim, para minha família, para todos nós em relação a este lugar, no passado, agora e no futuro.

Na medida em que continuo nessa jornada de verdade e reconciliação le não de forma não problemática), meu reconhecimento territorial continua a evoluir. Atualmente, termina com: 0 que eu aprecio nessa foto - e por que a compartilho com você - é que ela representa visualmente uma história colonial compartilhada e nosso complexo presente de residir neste lugar. Isso me lembra, enquanto ando de bicicleta, meu privilégio de descendente dos colonos Menonitas que receberam terras, da dívida que temos e da minha responsabilidade de viver aqui de uma maneira boa, juntos em relação aos outros, e em particular àqueles a quem essa terra pertence.

\section{REFERÊNCIAS}

BRASS, T. Speaker raises issue with traditional territories acknowledgement in lecture. The Manitoban, Manitoba, 11 out. 2018. Disponivel em: http://www.themanitoban.com/2018/10/indigenous-prof-critical-of-u-of-m-land-acknowledgement/35407. Acesso em: 24 nov. 2019.

CARREIRO, D. "You had no choice": indigenous Manitobans shed light on exploitative farm labour program that ran for decades. CBC Manitoba, Manitoba, 18 jun. 2017. Disponivel em: https://www.cbc.ca/ news/canada/manitoba/indigenous-forced-labour-sugar-beet-farms-1.4165272. Acesso em: 24 nov. 2019.

CRAFT, A. Breathing life into the stone fort treaty: an anishinabe understanding of treaty one. Saskatoon, SK: Purich Publishing Limited, 2013.

DONALD, D. Forts, colonial frontier logics, and Aboriginal-Canadian relations: imagining decolonizing educational philosophies in Canadian contexts. In: ABDI, A. A. (ed.). Decolonizing Philosophies of Education. Rotterdam: Sense Publishers, 2012. p. 91-111.

HERGESHEIMER, J. Unceded territory: meaningfully acknowledging Coast Salish peoples. Megaphone Magazine, 18 mar. 2016. Disponivel em: http://www.megaphonemagazine.com/unceded_territory. Acesso em: 24 nov. 2019.

KLASSEN, J. Mennonites, Métis and First Nations. Steinbach Village News Blog, Steinbach, 9 ago. 2018. Disponivel em: https://www.mysteinbach.ca/blogs/9111/mennonites-metis-and-first-nations-people/. Acesso em: 24 nov. 2019.

LEDOHOWSKI, E. The heritage landscape of the crow wing study region of southeastern Manitoba. Manitoba: Manitoba Culture, Heritage and Tourism, 2003. Disponivel em: https://www.gov.mb.ca/chc/ hrb/internal_reports/crow_wing_study.html. Acesso em: 24 nov. 2019. 
MARACLE, L. Memory serves: oratories. Edmonton: NeWest Press, 2015.

TUCK, E.; GAZTAMBIDE-FERNÁNDEZ, R. A. Curriculum, replacement, and settler futurity. JCT: Journal of Curriculum Theorizing, v. 29, n. 1, p. 72-89, 2013.

TUCK, E; Y YNG, K. W. Unbecoming claims: pedagogies of refusal in qualitative research. Qualitative Inquiry, v. 20, n. 6, p. 811-818, 2014.

UNIVERSITY OF MANITOBA. Traditional Territorial Acknowledgement. Manitoba: University of Manitoba, 2019. Disponível em: http://umanitoba.ca/admin/indigenous_connect/5728.html. Acesso em: 24 nov. 2019.

Endereço para correspondência: Room 230, Education Building, 71 Curry Place, University of Manitoba (Fort Garry Campus), Winnipeg, MB R3T 2N2 Canada; melanie.janzen@umanitoba.ca 